\title{
ATIVIDADE ANTIRRADICAL LIVRE DE COMPOSTOS BIOATIVOS DE SOJA PRETA (Glycine max L. Merril)
}

\author{
T. C. F. ESTEVES ${ }^{1}$, A. F. FARIA-MACHADO ${ }^{2}$, I. FELBERG ${ }^{2}$, R. ANTONIASSI ${ }^{2}$, M. C. \\ CARRÃO-PANIZZI ${ }^{3}$, V. M. A. CALADO ${ }^{1}$, J. N. PEREIRA ${ }^{4}$ \\ ${ }^{1}$ Universidade Federal do Rio de Janeiro, Escola de Química \\ ${ }^{2}$ Embrapa Agroindústria de Alimentos \\ ${ }^{3}$ Embrapa Trigo \\ ${ }^{4}$ Universidade Federal Rural do Rio de Janeiro \\ E-mail para contato: thianaesteves@gmail.com
}

\begin{abstract}
RESUMO - A soja preta (Glycine max L. Merril), pouco conhecida no ocidente, tem despertado a atenção de pesquisadores e consumidores para seu potencial promotor de saúde devido à presença de antocianinas na casca. Considerando a importância do Brasil na produção mundial de soja, o conhecimento desta cultivar apresenta-se como uma oportunidade de desenvolvimento desta cultura no país. Este trabalho teve como objetivo extrair compostos bioativos de soja preta e estimar sua atividade antioxidante. Os compostos bioativos foram extraídos com solução metanólica $60 \%$ com $1 \%$ de $\mathrm{HCl} \mathrm{em}$ ultrassom por 20 e 30 minutos em duas etapas, o teor de antocianinas totais foi determinado pela absorbância a $535 \mathrm{~nm}$ e a atividade antioxidante estimada por meio do ensaio de DPPH. A extração por 30 minutos foi mais adequada apresentando concentração média de antocianinas de $90,8 \mathrm{mg} / 100 \mathrm{~g}$, tendo o extrato apresentado EC50 de $0,14 \mathrm{mg} / \mathrm{L}$. Os resultados confirmaram o importante potencial antioxidante da soja preta.
\end{abstract}

\section{INTRODUÇÃO}

A soja preta (Glycine max L. Merril) é uma variedade de soja, ainda pouco conhecida no ocidente, que tem despertado a atenção de pesquisadores e consumidores para o seu potencial promotor de saúde. Há centenas de anos é utilizada como alimento saudável e extrato herbal na China, Índia, Coréia e Japão (Xu e Chang, 2008) e estudos têm revelado que os efeitos benéficos à saúde atribuídos ao seu consumo são devidos à presença de fitoquímicos. Dentre os principais compostos bioativos contidos na soja preta estão as isoflavonas e as antocianinas, estas últimas presentes apenas em variedades de soja com tegumento preto (Ha et al., 2009).

Pesquisas têm demonstrado que a soja preta, pelos seus compostos bioativos, possui atividade antidiabetes (Kanamoto et al., 2011), antiobesidade (Kim et al., 2007; Do et al., 2011), anticâncer (Kim et al., 2008; Slavin et al., 2009; Ye e Ng, 2011; Zou e Chang, 2011), anti-inflamatória (Kim et 


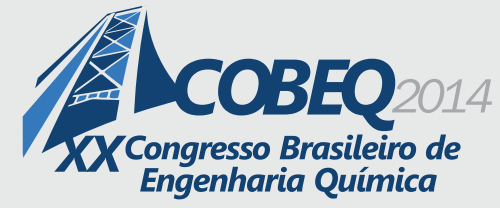

al., 2008; Kim et al., 2011), hipolipidêmica (Takahashi et al., 2005; Slavin et al., 2009) e antimutagênica (Hung et al., 2007), entre outras. Estas propriedades têm despertado o interesse dos consumidores para os potenciais benefícios do consumo da soja preta, com consequente aumento da demanda por produtos derivados do grão.

Antocianinas são flavonoides responsáveis por uma grande variedade de coloração das plantas, incluindo azul, roxo, violeta, magenta, vermelho e laranja (Domodarans et al., 2008). Além de seus efeitos na coloração de frutas, as antocianinas são reconhecidas como ingredientes promotores de saúde em função de sua capacidade antioxidante. Constituem os principais pigmentos da soja preta, sendo encontrados principalmente na casca das sementes (Koh et al., 2014).

De acordo com dados divulgados pela Companhia Nacional de Abastecimento (CONAB) no sexto levantamento de produção de grãos da safra 2013/14 a soja deve gerar a colheita de $85.442,5$ milhões de toneladas, mantendo-se como segundo maior produtor mundial de soja, logo atrás dos Estados Unidos. O importante papel que o Brasil desempenha na produção mundial de soja, fortalece a oportunidade do desenvolvimento da cultura da soja preta no Brasil e o provimento de novos produtos pela indústria nacional.

Apesar da intensa divulgação das propriedades benéficas da soja preta na mídia, informações técnico-científicas a respeito deste tipo de soja ainda são escassas no Brasil. O presente trabalho teve como objetivo estimar a atividade antioxidante de soja preta adquirida no mercado nacional através da desativação de radicais livres, pelo método DPPH.

\section{MATERIAIS E MÉTODOS}

\subsection{Material}

Grãos de soja preta foram adquiridos a granel em mercado varejista na cidade de São Paulo (Brasil). Os grãos foram moídos em moinho de martelo (Laboratory Mill 3100) que permite moer a partícula de forma a propiciar uma maior superfície de contato e desta forma facilitar a extração dos compostos bioativos.

\subsection{Extração de compostos bioativos dos grãos de soja preta}

Dois procedimentos de extração em duplicata foram avaliados. O primeiro consistiu de uma dupla extração de um grama de soja preta moída com $25 \mathrm{~mL}$ de solução metanólica $60 \%$ com $1 \%$ de $\mathrm{HCl}$, por meio de agitação em ultrassom (Soniclean SW 2000) por 20 minutos a $40{ }^{\circ} \mathrm{C}$. O segundo procedimento diferiu do primeiro no tempo de extração no ultrassom que foi de 30 minutos. Após a primeira extração, os sobrenadantes foram recuperados por meio de centrifugação (10.000 RPM, por 10 min, a $4^{\circ} \mathrm{C}$ ) e as amostras foram submetidas a uma segunda extração com mais $25 \mathrm{~mL}$ de solução extratora, totalizando em 4 leituras por procedimento. Os extratos foram acondicionados em frascos âmbar e armazenados a $-18^{\circ} \mathrm{C}$.

\subsection{Antocianinas}




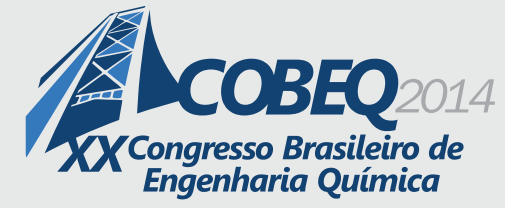

O conteúdo de antocianinas totais nos extratos metanólicos de soja preta foi determinado de acordo com Francis (1982), utilizando como solvente etanol 95\%/HCl 1,5N $(85: 15) \mathrm{v} / \mathrm{v}$, por meio de leitura da absorbância a $535 \mathrm{~nm}$ em espectrofotômetro UV-Visível (Agilent, modelo 8453) O conteúdo de antocianinas totais foi calculado de acordo com a Lei de Beer (Equação 1), considerando o somatório das duas extrações realizadas com cada amostra.

\section{Antocianinas Totais $=A \times F D / \varepsilon($ Equação 1$)$}

Sendo:

A = valor da absorbância

$\mathrm{FD}=$ fator de diluição $=2,50$

$\varepsilon=\mathrm{A}^{1 \%}{ }_{1 \mathrm{~cm}}=$ coeficiente de absorção (considerando passo óptico de $1 \mathrm{~cm}$ )

Eantocianinas $=98,2 \mathrm{~L} / \mathrm{g} . \mathrm{cm}$

\subsection{Atividade antioxidante}

A atividade antioxidante dos extratos foi estimada por meio do ensaio de DPPH que consiste na redução do radical estável 2,2-diphenyl-1-picrylhydrazyl (DPPH) em solução metanólica pelo extrato ou composto antioxidante, de acordo com o método descrito por Brand-Williams et al. (1955). Uma alíquota $(0,1 \mathrm{~mL})$ de diferentes diluições do extrato foi misturada a $3,9 \mathrm{~mL}$ de solução metanólica de DPPH e a desativação do radical livre foi monitorada por meio de leitura da absorbância a $515 \mathrm{~nm}$ após 15 min de reação. Os percentuais de DPPH remanescente foram calculados utilizando os valores de absorbância obtidos com cada diluição de extrato, sendo estes resultados utilizados para obtenção de curvas de porcentagem de DPPH remanescente em função da concentração de antocianinas totais. A atividade antioxidante foi expressa como a quantidade de extrato necessária para reduzir em $50 \%$ a concentração inicial de DPPH $\left(\mathrm{EC}_{50}\right)$. A contribuição das antocianinas dos extratos para a absorbância em $515 \mathrm{~nm}$ foi verificada considerando a diluição utilizada para a realização do ensaio $(0,1 \mathrm{~mL}$ de extrato $+3,9 \mathrm{~mL}$ de metanol), sendo que essa contribuição não foi significativa, podendo ser desconsiderada na estimativa da atividade antioxidante. Trolox (6-Hidroxi-2,5,7,8tetrametilchroman-2-ácido carboxílico) foi utilizado como antioxidante de referência.

\section{RESULTADOS E DISCUSSÃO}

Conforme mostra a Figura 1, os extratos obtidos a partir da soja preta apresentaram coloração rosa característica da presença de antocianinas. A diferença nas tonalidades sugere a diferença de concentração deste composto em função do tempo de extração. 


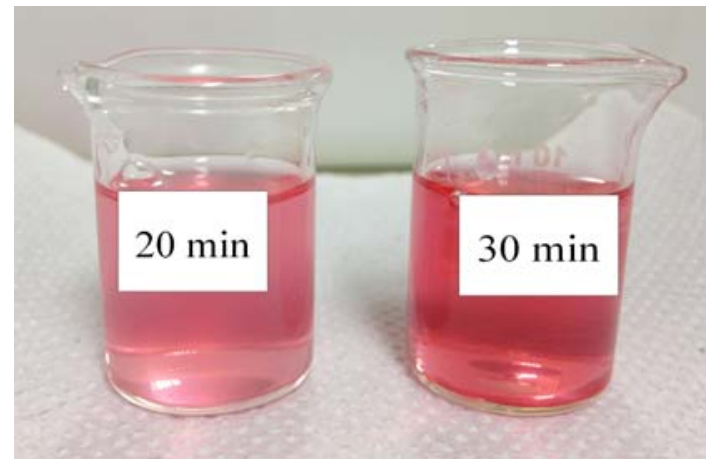

Figura 1 - Extratos obtidos após 20 min. e 30 min. de extração

A determinação da concentração de antocianinas totais obtida nas extrações por 20 e 30 minutos (Tabela 1) permitiu confirmar que o procedimento por 30 minutos foi mais adequado devido a maior eficiência de extração gerando, consequentemente, resultados mais confiáveis na estimativa da atividade antirradical livre.

Tabela 1 - Valores médios de Antocianinas Totais (AT) para 20 e 30 minutos de extração.

\begin{tabular}{ccc}
\hline Procedimento & Tempo de extração $(\mathrm{min})$ & AT $(\mathrm{mg} / 100 \mathrm{~g})$ \\
\hline 1 & 20 & 83,760 \\
2 & 30 & 91,131 \\
\hline
\end{tabular}

Os valores de antocianinas encontrados para a soja preta utilizada neste estudo estão de acordo com os resultados apresentados por Zhang et al. (2011) que avaliaram as antocianinas presentes em sessenta variedades de soja preta originárias da China, obtendo valores entre de 98,8 a 2132,5 $\mathrm{mg} / 100 \mathrm{~g}$.

Quanto a atividade antioxidante os extratos obtidos da soja preta nas extrações de 20 e 30 minutos apresentaram valores de $\mathrm{EC}_{50}$ entre 0,12 e $0,14 \mathrm{mg} / \mathrm{L}$. Embora os extratos obtidos em diferentes tempos apresentem concentrações diferentes de antocianinas totais, era esperado que ambos apresentassem valores muito próximos de $\mathrm{EC}_{50}$. Isto ocorre porque o $\mathrm{EC}_{50}$ é obtido a partir de medições de atividade do extrato em diferentes diluições, sendo calculada na sequência, por meio de ajustes matemáticos, a concentração do composto antioxidante, neste caso antocianinas totais, que permite obter $50 \%$ de desativação do radical livre. Além disso, é necessário considerar que ambos os extratos (20 e 30 minutos) foram obtidos a partir de uma mesma matéria-prima, utilizando o mesmo procedimento de extração, com diferença apenas no tempo, de forma que é esperado que estes extratos contenham perfis muito parecidos em termos de tipos e proporções relativas de antocianinas, que são fatores que poderiam modificar a atividade antioxidante dos extratos em estudo.

Os valores de $\mathrm{EC}_{50}$ obtidos neste estudo para os extratos de soja preta são bastante promissores, considerando que o valor de $\mathrm{EC}_{50}$ obtido para Trolox nos ensaios realizados em paralelo à avaliação dos extratos de soja preta foi de $4,8 \mathrm{mg} / \mathrm{L}$ de Trolox, lembrando que quanto menor o valor de $\mathrm{EC}_{50}$, maior a atividade antioxidante do composto em avaliação. 


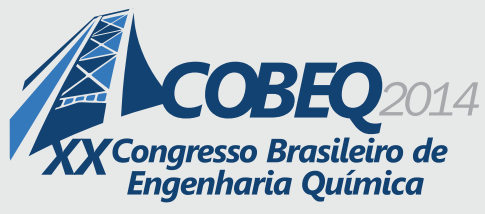

\section{CONCLUSÕES}

A metodologia utilizada foi eficiente para a extração de compostos de soja preta, sendo a dupla extração por 30 minutos o procedimento mais adequado. $\mathrm{O}$ teor de antocianinas totais encontrado no extrato de soja preta é comparável àqueles encontrados em outros trabalhos realizados com diferentes variedades de soja preta. Os resultados obtidos neste trabalho indicam que a soja preta estudada apresenta importante potencial antioxidante frente à desativação de radicais livres, tendo apresentado valores de $\mathrm{EC}_{50}$ de 0,12 a $0,14 \mathrm{mg} / \mathrm{L}$. Contudo, mais estudos são importantes para consolidação da soja preta como alimento com alegação de saúde.

\section{REFERÊNCIAS}

BRAND-WILLIAMS, W.; CUVELIER, M. E.; BERSET, C. Use of a free radical method to evaluate antioxidant activity. Food Sci. Technol., v. 28, p. 25-30, 1995.

CONAB - COMPANHIA NACIONAL DE ABASTECIMENTO. Acompanhamento da safra brasileira de grãos. v. 1, safra 2013/2014, n.6 - sexto levantamento, março/2014.

DAMODARAN, S.; KIRK, P.; FENNEMA, O.R. Fennema's Food Chemistry. 4a ed. CRC Press, 2008.

DO, K.; JEUN, J.; HOUNG, S-J.; JUN, H-J.; LEE, J. H.; JIA, Y.; LEE, S-J. Soybean (Glycine max L. Merr.) hexane extracts inhibit cellular fatty acid uptake by reducing the expression of fatty acid uptake by reducing the expression of fatty acid transporters. Food Sci. Biotechnol., v. 20, n.1, p. 237-242, 2011.

HA, T. J.; LEE, J. H.; SHIN, S-O.; SHIN, S-H., HAN S-I.; KIM, H-T.; KO, J-M.; LEE, M-H.; PARK, K-Y. Changes in anthocyanin and isoflavone concnetrations in black seed-coated soybean at different planting location. J. Crop Sci. and Biotech. v. 12, n. 2, p. 78-86, 2009.

HUNG, Y. H.; HUANG, H. Y.; CHOU, C. C. Mutagenic and antimutagenic effects of methanol extracts of unfermented and fermented black soybeans. Int. J. Food Microbiol., v. 118, p. 62-68, 2007.

KANAMOTO, Y.; YAMASHITA, Y.; NANBA, F.; YOSHIDA, T.; TSUDA, T.; FUKUDA, I.; NAKAMURA-TSURATA, S.; ASHIDA, H.. A black soybean seed coat extract prevents obesity and glucose intolerance by up-regulating upcoupling proteins and down-regulating inflammatory cytokines in high-fat diet-fed mice. J. Agric. Food Chem., v. 59, p. 8985-8993, 2011.

KIM, H. J.; BAE, I. Y.; AHN, C-W.; LEE, S.; LEE, H. G. Purification and identification of adipogenesis inhibitory peptide from black soybean protein hydrolysate. Peptides. v. 28, p. 20982103, 2007.

KIM, J-M.; KIM, J-S.; YOO, H.; CHOUNG, M-G.; SUNG, M-K. Effects of black soybean [Glycine max (L.) Merr.] seed coats and its anthocyanidins on colonic inflammation and cell proliferation in vitro and in vivo. J. Agric. Food Chem., v. 56, p.8427-8433, 2008.

KIM, K.; LIMB, K-M.; KIMB, C-W.; SHINB, H-J.; SEOB, D-B.; LEEB, S-J.; NOHA, J-Y.; BAEA, O-N.; SHINC, S.; CHUNGA, J-H. Black soybean extract can attenuate thrombosis through 
inhibition of collagen-induced platelet activation. J. .Nutri. Biochem., v. 22, p. 964-970, 2011.

KOH, K.; YOUN, J. E.; KIM, H-S. Identification of anthocyanins in black soybean (Glycine max (L.) Merr.) varieties. J. Food Sci. Technol. v. 51(2), p. 377-381, 2014.

SLAVIN, M.; KENWIRTHY, W.; YU, L. L. Antioxidant properties, phytochemical composition, and antiproliferative activity of Maryland-grown soybeans with colored seed coats. $J$. Agric. Food Chem., v. 57, p. 11174-11185, 2009.

TAKAHASHI, R.; OHMORI, R.; KIYOSE, C.; MOMIYAMA, Y.; OHSUZU, F.; KONDO, K. Antioxidant activities of black and yellow soybeans against low density lipoprotein oxidation. $J$. Agric. Food Chem., v. 53, p. 4578-4582, 2005.

XU, B.; CHANG, S.K.C. Antioxidante capacity of seed coat, dehulled bean, and whole black soybean in relation to their distribution of total phenolics, phenolic acids, anthocyanins, and isoflavones. J. Agric. Food Chem., v. 56, p. 8365-8373, 2008.

YE, X. J.; NG, T. B. Antitumor and HIV-1 reverse transcriptase inhibitory activities of a hemagglutinin and a protease inhibitor from mini-black soybean. Evid-based. Compl. Alt. v. 2011, p. $1-12,2011$.

ZHANG, R. F.; ZHANG, F. X.; ZHANG, M. W.; WEI, Z. C.; YANG, C. Y.; ZHANG, Y.; TANG, X. J.; DENG, Y. Y.; CHI, J. W. Phenolic composition and antioxidant activity in seed coats of 60 chinese black soybean (Glycine max L. Merr.) varieties. J. Agric. Food Chem. v. 59, p. 59355944, 2011.

ZOU, Y.; CHANG, S. K. C. Effect of black soybean extract on the suppretion of the proliferation of human AGS gastric cancer cells via the induction of apoptosis. J. Agric. Food Chem., v. 59, p. 4597-4605, 2011. 